\title{
Regulation of environmental protection measures in the Caspian Sea region
}

\author{
Sergey Yekimov ${ }^{1, *}$, Oleg Bavykin ${ }^{2}$, Elena Kuznetsova ${ }^{3}$, Roman Kucherenko ${ }^{4}$, and Dmitriy \\ Kucherenko ${ }^{4}$ \\ ${ }^{1}$ Publishing House "Education and Science" s.r.o., Olstynska 607/1, 18100 Praha 8, Czech Republic \\ ${ }^{2}$ Moscow Polytechnic University, Moscow, Russian \\ ${ }^{3}$ Kirov State Medical University, Kirov, Russian \\ 4“Kuban State Agrarian University named after I.T. Trubilin”, Krasnodar, Russian
}

\begin{abstract}
Information obtained as a result of monitoring of water bodies is taken as a basis for legal regulation of economic activities related to environmental pollution. In the context of a globalized economy, the strengthening of environmental protection measures in one of the neighboring countries often leads to the fact that the next plant will be built across the border, and its impact on the environment on a global scale will be the same. In this study, the authors studied the problem of finding new ways to solve the environmental problems of the Caspian Sea. The Caspian Sea belongs to Kazakhstan, the Russian Federation, Turkmenistan, Azerbaijan and Iran. to solve the environmental problems of the Caspian Sea, it is necessary to unify the environmental legislation of these countries, similar to the unification of the environmental legislation of the European Union countries.
\end{abstract}

\section{Introduction}

Monitoring of water objects is the collection, processing and delivery of information obtained for the purpose of regular monitoring of hydrological, hydrogeological, hydrogeochemical, sanitary-chemical, microbiological, parasitological, radiological and Toxicological indicators of timely revealing of negative processes, assessment and prediction of waste system recommendations on prevention and elimination of the adverse effects of the proposed action on water resources management. Various types of monitoring of water bodies are considered in $[1,2,3,4,5,6]$, the negative impact of human activity on the state of the Caspian Sea was studied in [7,8,9,10,11,12], in the article [5] recommendations for improving environmental monitoring at the interstate level are proposed. This indicates the relevance of further study of the legal regulation of the ecological state of the Caspian Sea.

According to Article 19 of the Framework Convention for the Protection of the Marine Environment of the Caspian Sea [13], the Contracting Parties shall perform the following duties:

\footnotetext{
${ }^{*}$ Corresponding author: $\underline{3701313 @ \text { mail.ru }}$
} 
1. Seek to establish and implement appropriate independent and / or joint monitoring programmes for the marine environment of the Caspian Sea.

2. Agree on the list and criteria of pollutants that are controlled in the Caspian Sea for emissions and production.

3. Independently and / or jointly assess the effectiveness of the assessment of the state of the Caspian Sea and develop measures aimed at limiting, reducing and preventing pollution of the Caspian Sea.

4. Agree on rules for data monitoring and processing programs, as well as their quality assessment.

5. Provide a framework for decision-making and a centralized database that is a common source of information and knowledge for professionals, administrators.

\section{Materials and methods}

In this paper, the system of monitoring the ecological state of the Caspian Sea and ways of implementing environmental measures were analyzed. Based on the analysis, the conclusion is made about the need for a comprehensive approach that provides for further unification of environmental legislation in the Caspian region.

\section{Results}

In our opinion, in modern conditions, the problem of developing a more optimal legal regime for the use of natural resources of the Caspian Sea, as well as carrying out measures to protect the environment, is steadily increasing. Modern international law contains a large number of norms that relate to various issues of the use of natural resources and, first of all, the burial and transportation of industrial waste.

The Framework Convention for the Protection of Marine Resources of the Caspian Sea [13] includes all five Caspian countries: Azerbaijan, the Russian Federation, Iran, Turkmenistan and the Republic of Kazakhstan.

All these states produce hydrocarbons from the sea, so they should, in our opinion, jointly solve the problems associated with the release of pollutants into the Caspian Sea, as well as develop measures to control the degree of pollution of the Caspian Sea. Environmental measures taken unilaterally by only one of the states, in our opinion, will not give the proper effect, but will only contribute to an increase in hydrocarbon production in countries where environmental legislation is less strict, which means that the volume of emissions of harmful substances into the Caspian Sea will not decrease.

Therefore, in our opinion, it is necessary to develop various internal interstate acts or regulations on the regulation of individual subjects of the Caspian states regarding the Caspian Sea. Accordingly, based only on the word "framework", it should be understood that this type of convention does not provide a document regulating all aspects of the protection of the environment of the Caspian Sea. we should not forget that the framework nature of the Tehran convention reflects the possibility of forming additional regulatory documents to the convention, as well as the signing of bilateral and multilateral treaties between the Caspian countries. This is the reason for the creation of a legal instrument that will consider the articles of the convention more broadly and in detail, as separately taken. When assessing this phenomenon, not a single regulatory act regulating this activity was identified. That is why, in our opinion, it is important to develop and adopt national regulatory legal acts in each Caspian state, which will be aimed at protecting the environment of the Caspian Sea, which will take into account such aspects as fishing, import and export of goods through the Caspian Sea. Legalize equal production without 
harming the environmental situation, and clearly distribute measures controlling poaching and shipping. intensive use of vessels for transportation of oil produced in the Caspian Sea region and oil products produced from it causes significant potential risks associated with water pollution.

In addition, due to poaching, the population of sturgeon fish in the Caspian Sea has sharply decreased. Although the Ministry of Natural Resources and Ecology of the Russian Federation is actively fighting this problem, however, in our opinion, this is not enough to solve this problem. We believe that it is necessary to develop and sign international agreements that more closely coordinate the activities of environmental and law enforcement agencies of all countries of the Caspian region.

This should form the overall structure of relations between the Caspian countries, as well as contribute to a more sustainable and stable development of the entire region.

The national legislation of all the Caspian countries is of great importance in regulating the protection and use of natural resources in the Caspian Sea. At the same time, due to corruption and lack of financial resources allocated for environmental protection measures, these laws are not being implemented satisfactorily.

Unified requirements for environmental protection exist in the countries of the European Union, so, in our opinion, it can be very effective to create uniform requirements for economic activities in the Caspian Sea region, including in matters related to the management of industrial waste.

In our opinion, the problem of preventing the consequences of various accidents and emergencies that have a negative impact on the Caspian Sea is also very important. In modern conditions, each of the Caspian littoral countries does not have modern means and infrastructure to eliminate the consequences of such accidents. Given that the development of hydrocarbons on the shelf of the Caspian Sea is growing steadily every year, we believe that all the Caspian countries should develop international legal mechanisms for environmental protection, taking into account the problematic aspects. this will, in our opinion, make a great contribution to the preservation of this natural complex.

\section{Discussion}

Consideration of the legal regulation of economic activity on the ecological state of the Caspian Sea requires a more detailed study. Theoretical analysis has shown that in the studies of different authors there are different approaches to solving this problem. Most often, we are talking about the recommendation to establish any restrictions on the economic activities of economic entities. These restrictions are often developed without taking into account the interests of enterprises responsible for pollution of the Caspian Sea, and it is often easier for them to pay a fine or look for any other ways than to comply with these restrictions.

In our opinion, it is necessary to involve more widely in the development of environmental legislation not only representatives of regulatory structures, scientists, but also enterprises of the most polluting Caspian Sea, primarily oil producing and refining companies, of all countries.

The final result should be the unification of the environmental legislation of the countries of the Caspian region, as it is done with the environmental legislation in the countries of the European Union. 


\section{Conclusions}

Due to the fact that the Convention [13] provides for the right of each of the Caspian countries to free movement by all means of transport to other oceans and seas, and the process of approving projects for laying pipelines on the seabed, taking into account the verification of environmental safety, is a long and complex process. In our opinion, it is necessary to create uniform requirements for the laying of such communications. This, in our opinion, will contribute not only to the greater preservation of natural resources, but also to a more dynamic development of the region's economy (Figure 1).
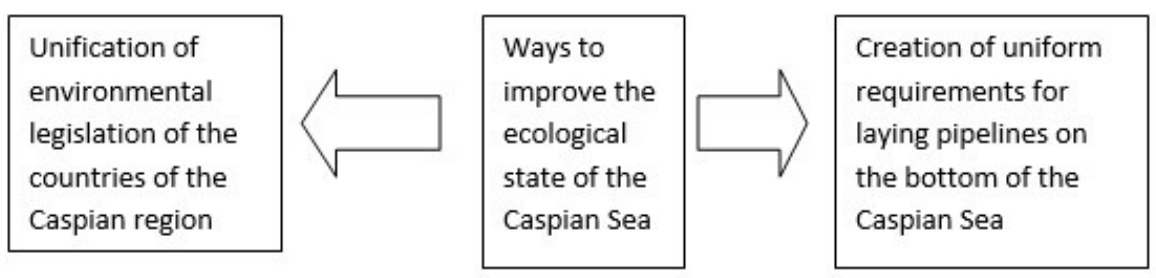

Fig. 1. Ways to improve the ecological state of the Caspian Sea.

In our opinion, the oil companies of the Caspian states should take part in today's consortia to determine the wealth of the Caspian Sea. In the course of field development between two or more areas, there is a need for appropriate production sharing agreements between States. In our opinion, the countries of the region should take a more active part in agreements, including condominiums, on the opportunities of the Caspian Sea, including on shipping, fishing and environmental protection. At the same time, we believe that each state should have agreed on cross-border territorial waters, that is, their fishing zone should be located within one state. The rest of the sea should be open to navigable navigation between States.

Our proposals on the legal status of the Caspian Sea include the experience of using mineral resources and international standards not only for the use of mineral resources, but also the experience of using the wealth of the Caspian basin between the USSR and Iran.

\section{References}

1. N. Jafari, Journal of Ecology and the Natural Environment 2, 25 (2010)

2. E. Lari, B. Abtahi, M. Seyed Hashtroudi, Aquatic Toxicology 170, 330 (2016)

3. D.N. Katunin, S.N. Yegorov, I.A. Khripunov, E.A. Kravchenko, N.V. Galushkina, G.V. Radovanov, A.V. Azarenko, The main characteristics of hydrologicalhydrochemical regime in the lower reaches of the Volga River in 2002. In "Fisheries Researches in the Caspian:Scientific-research works results for 2002", Astrakhan (2003)

4. D.N. Katunin, S. N. Yegorov, I.A. Khripunov, et.al, Main characteristics of hydrologicalhydrochemical regime in the lower reaches of the Volga River in 2003. In "Fisheries Researches in the Caspian: Scientific-research works results for 2003", Astrakhan (2004)

5. A. Korshenko, A.G. Gul, Hdb. Env. Chem. 5, 109 (2005)

6. A. Korshenko, A Desk Study Project to determine the fluxes of major contaminants (2007)

7. Zt. Lobat, Integrated Environmental Assessment as a Comprehensive Governance Tool for the Caspian Littoral States to Control the Environmental Degradations (2018) 
8. S. Harris-Brandts, D. Gogishvili, Eurasian Geography and Economics 1-25 (2018)

9. N. Sivri, K. Ozcan, E. Başar, F. Ahmadli, Oil contamination damage and the marine biodiversity: Caspian Sea and Black Sea (2016)

10. B. Mirnategh, N. Shabanipour, M. Sattari, Seawater, Sediment and Fish Tissue Heavy Metal Assessment in Southern Coast of Caspian Sea (2018)

11. H. Eronat, Deu Engineering Faculty Science and Engineering 21, 47 (2019)

12. T. Härkönen, M. Baimukanov, A. Bignert, et.al, EIA. Caspian Sea Region: Survey of Key Oil and Gas Statistics and Forecasts, July 2006 (2008)

13. Framework Convention protection of the marine environment of the Caspian sea (Tehran, 4 November 2003) 